\title{
Discussion on Japan's Animation Culture and Its Influence
}

\author{
Meng Wang \\ School of foreign languages, Dalian Jiaotong University Dalian, 116033, China
}

Keywords: Japan, animation culture, teenagers, influence

\begin{abstract}
Japanese animation has already become a sort of animation culture and animation industry popular all over the world. Through typical works in Japanese animation, we can find that Japanese animation has naturalistic style, and that it can realize dynamic integration between Japanese culture and foreign cultures. Japanese animation has great effects on Chinese teenagers. In this paper, the author summarizes basic meaning of animation, analyzes main characteristics of Japanese animation, and discusses the influence of Japanese animation on Chinese teenagers.
\end{abstract}

\section{Basic Meaning of Animation}

The concept of animation appeared in Japan in the 1960s, and it was firstly proposed by Japanese animation master Osamu Tezuka. Initially, Chinese animation only equaled to the word “cartoon”. However, “卡通” in Chinese is the transliterated as "cartoon" in English. With the implementation and the reform and opening-up policy in China, animation entered Chinese market. Mickey and Donald popular in the world in the 1980s still remain fresh in people's memory. However, animation doesn't mean simple cartoon. Animation itself contains both parts of cartoon and comic. Animation refers to dynamic scenes frequently seen in television or movie. However, the origin of animation is even earlier. It mainly includes continuous static pages that can be read by readers, so as to obtain a visually dynamic sense. Therefore, animation is a group of entertainment symbols derived from cartoon and comic.

\section{Main Characteristics of Japanese Animation}

Japan is the biggest animation production and exportation country in the world at present. Its animation products have already formed a set of complete industrial chains, promoting continuous development of Japan's economy. At the same time, for better development of its animation culture and animation industry, Japanese government begins to positively expand animation broadcasting, animation derivatives and other markets, so as to make the development of Japanese animation to remarkably surpass China. With its unique characteristics, Japanese animation conquers cartoon fans all over the world. Main characteristics of Japanese animation are described as follows:

\section{(I) Extremely Morbid Beauty}

Japan obstinately pursue for extreme beauty. For instance, Japanese people think that the most beautiful moment is the moment in which cherry blossoms wither and fall. The reason is that it is very fast for cherry blossoms in a tree to wither and fall, and that the destruction scene is very spectacular. Therefore, it is inspiring. Japanese people pursuing for beauty even at the instant moment of death certainly will run to extremes with respect to creation of animation art, or even pursue for a sort of morbid beauty. Reflected in animation works, it results in almost crazy homosexual plots in Mirage of Blaze and Absolute Love as well as deliberate beautification and processing of massacre scenes in Rurouni Kenshin. Readers can't help associating Japanese Samurai spirit. Bushido requires a samurai to get well prepared for devoting his life at any time, and reach a certain crazy level for so-called career. Therefore, samurais will resolutely choose to commit ritualistic suicide when they are faced with failure, and frequently research how to make ritualistic actions more beautiful. Viewed by other countries, this action making Japanese people proud of is typical morbidity.

\section{(II) Exquisite Emotional Description}

Japanese animation creators are good at describing subtle emotions between figures. Moreover, they pay special attention to description on details. Usually, considerable dialogues or asides are produced in animation works. Above discourses inevitably will be revealed naturally with changes in inner emotional world of animation figures. Thus, figures will become more colorful and more vivid. Delicate description on figure's inward world is one of important features of Japanese animation works as well as one of significant signs used by us to distinguish Japanese animation from American animation. Then, why Japanese animation has such characteristics? The reason is that Japanese people will not easily reveal their inner emotions. If it continues this way for a long time, their sense organs will become extremely developed and can meticulously feel delicate emotions between them. Thus, attention on emotional relations between people and people becomes priority in their life. Japanese people 
will pay close attention to other's evaluation for themselves as well as interpersonal communication. Therefore, figures' inner world and emotional life is very familiar animation theme for Japanese people with quite exquisite emotions.

\section{(III) Pessimistic Mood Everywhere}

Japan has extremely narrow territory and extremely insufficient resources, while earthquake, typhoon and other natural disasters are very frequent. Many people are leaded to an uneasy survival. Inconstancy of the nature brings about a sort of helpless sense to modern people, letting insecurity to deeply implant to Japanese people's hearts. Uncertainty and insecurity for the future already become frequently seen pessimistic emotions in Japanese culture. In the severe cases, that even evolves into a negative and pessimistic phenomenon. This phenomenon is seen in considerable Japanese animation works. For instance, Neon Genesis Evangelion is a representative for such animation works. In this book, people fail to fight against foreigners at the arrival of the end of the world. Seriously, mutual suspicion, jealousy and evil of human nature accelerate the coming of the disaster, leading to destruction of humans. In the end, a large sheet of darkness is shown to audiences. It is so silent that audients feel smothery.

\section{(IV) War-themed Works with Vague Good and Evil}

War is a theme that can be frequently found in Japanese animation works. However, great difference from frequently seen war-themed works with distinct good and evil is that positive and negative characters with clear-cut stands are seldom found in war-themed Japanese animation works. Thus, there is no bad person in a war. Since neither party has bad person in the war, reasons for the war are unsmooth communication and unclear comprehension. Mistake occurs due to the failure to accurately understand each other, thus resulting in the war. In Japanese animation, devastated scenes are also used to describe and give a bitter account on the guilty of war. However, only the war itself is blamed for instead of both parties involved in the war. As the vanquished country in World War II, Japan is the unjust party. Suppose that it is analyzed according to normal good and evil theory, the fate of bad persons in animation works should be the fate for Japan as an unjust country launching the war. Japanese animation creators naturally are unwilling to see this circumstance, so they after careful thinking create this theory of justice frequently found in current Japanese animation works. Thus, the invaded country in Kyo Kara Maoh is serving the devil. Black saints in Saint Seiya are different from each other only in duty and justice. In Rurouni Kenshin, ninjas fight against each other due to different positions and different objects to be protected.

\section{Influence of Japanese Animation on Teenagers}

\section{(I) Positive Influence}

Firstly, it can effectively help teenagers to remit their psychological stress. At present, each modern person is under great pressure from colleges and universities and rapid rhythm of the society. Even college and secondary school students are also under such stress. Under stress from various parities, the students are unable to adapt to the utilitarianism society. As a result, teenagers are eager to find a dream land. Refusal to grow up so quickly has already become the common aspiration of teenagers. Therefore, Japanese animation becomes the most ideal bailment of their souls. In virtualized animation works, teenagers' energy unable to be embodied and relieved in reality can be relieved for a short period. Moreover, their fear and awful psychology can also be comforted to some extent, and the sense of alienation can be appropriately remedied and satisfied as the same time.

Secondly, animation can stimulate teenagers to make arduous efforts for their dreams. Personalities and experiences of many Japanese animation characters can allow adolescent readers to view their current conditions and future life that they are yearning for. Figures in Japanese animation obtain a sense of joy after experiencing great difficulties. Thus, animation fans are stimulated in this way, and deeply infected while appreciating animation works, so as to form positive, optimistic and high-spirited views of life. Besides, beautiful painting styles, gentle music and simple and impressive plots in animation works can remit teenagers' stress of academic record and communication in the real world, letting them to fight again, so as to struggle for success together with animation idols in their minds.

Thirdly, animation can help teenagers to display their personalities and strengthen their awareness of participation. For teenagers growing in the current diversified society, their perceptivity for arts exceeds that of adults. While fond of Japanese animation works, they can also create animation works of their own. However, charms of works above give an expression to wisdom and talented sense of humor of adolescent animation creators. At the same time, players can also choose their favorite roles to play in the creation process of animation games, so as to display their personalities in a better way in the virtualized world and get rid of various stresses from the real society.

\section{(II) Negative Influence}

Firstly, it is easy for superficial animation works to mislead adolescent readers. Some Japanese animation works are completely based on visual enjoyment of audiences. Due to very strong entertainment and relaxation, 
such works always can attract considerable teenagers to be addicted to these animation works. What's worse, it will mislead teenagers to take one-sided pursuit for enjoyment as their objectives of the struggle or secularized concepts as values of their life. Teenagers are too young to have enough judgment ability and resolving ability. If they lack fundamental directions, it will be even more difficult for them to distinguish or be willing to distinguish which prevalent culture is necessity of social life and which is only pure entertainment. Thus, some teenagers inevitably will follow so-called fashion blindly, only paying attention to appearance fashion and neglecting the improvement of connotation.

Secondly, violence, eroticism and similar elements exist in some Japanese animation works. For commercial value or due to unhealthy psychology, some Japanese animation creators will always create works with extremely bloody and violent contents, or even call it by a good name of violence aesthetics. Undoubtedly, this will cause great impacts to teenagers with immature physical and mental development. According to the results of the experiment made by a western psychologist, violence scenes can increase the aggressiveness of audiences, and induce the audiences to imitate offensive behaviors. This will inevitably affect ethics and thought morals created by school education and family education, letting teenagers to produce the superficial ethical concept of value as supremacy of physical strength. At the same time, another serious issue is the addition of pornographic contents. It can be said that eroticism is an element of Japanese animation culture that many people driven by economic benefit are crazy about under modern market economy. Unhealthy contents above will cause certain damages to teenagers' thought morals and psychological quality, and tempt teenagers to walk up along a crime road of no return.

Thirdly, animation has a great impact on native culture of China. Some teenagers are addicted to the world described in Japanese animation for a long time. Due to lack of necessary connoisseurship and aesthetic judgment, some teenagers often feel that culture suitable for their taste and value is good culture. Seriously, some teenagers even extremely think that cultures of European and American countries, Japan and Korea are fashionable. If it continues this way for a long time, a sort of xenocentric mentality will appear. Moreover, teenagers will be indifferent or even reject native culture of China. It is very easy for teenagers to take figures in many Japanese animation works as their idols. Due to the worship to their idols, teenagers will accept inner feeling of their values. Once teenagers fail to distinguish and completely accept militarism and other unhealthy thoughts concealed in some animation works, they may be assimilated by spirits of other nations, and lose national characters. That is just the deepest sorrow of a nation.

Fourthly, it is easy for animation to cause psychological problems. In real life, teenagers are confused by many questions all the time, resulting in their failure to give up any time quantum. The biggest hidden danger of this phenomenon is to lead teenagers to separate from reality. Survey has proved that teenagers may develop into eccentric persons, and be reluctant to communicate with others once they are excessively addicted to animation. Consequently, they are made to lack social skills.

\section{Conclusion}

Generally speaking, Japanese animation pays special attention to teenagers' thoughts and takes teenagers' innermost real needs as the basis for creation. In relaxed and vivid images, deep reflections on society and humanity are concealed in sensitivity of Japanese nation. In the pattern of animation work, young people can deepen their cognition for the world in relaxed and joyful atmosphere. Therefore, animation becomes intellectual food necessary for countless young people. With respect to the influence of Japanese animation culture on Chinese teenagers, different people have different comments in the critics circle. However, animation culture after all is the culture created and accepted by young people. It is very beneficial for the development of Chinese animation culture to have a correct understanding of Japanese animation culture and carefully understand and analyze the animation culture.

\section{References:}

[1] Jiang Bin, Characteristics of Japanese Animation Culture and Its Communication Strategies [J], Art Research, 2012 (3);

[2] Sun Ruixue, Exploration for Influence of Japanese Animation on College Students' Understanding of Japanese Culture [J], Jiannan Literature (Typical Teaching Institute), 2012 (10);

[3] Wu Xinlan, Analysis on Cultural Characteristics of Japanese Animation [J], Journal of Mudanjiang University, 2012 (11);

[4] Sheng Zhengzi, Patriotism Education under Influence of Animation Culture - Analysis on Influence of 
Animation of Japan and Other Foreign Countries on Young People in China [J], China-today Forum, 2013 (5); [5] Zhang Aihua, Discussion on Enlightenment of Japanese Animation Culture on Chinese Animation Development [J], Public Communication of Science \& Technology, 2014 (2) 